\title{
Boll weevil within season and off-season activity monitored using a
}

\section{pheromone-and-glue reusable tube trap}

\author{
Robério Carlos dos Santos Neves ${ }^{1}$, Jorge Braz Torres ${ }^{1 *}$, Eduardo Moreira Barros ${ }^{2}$, Lúcia Madalena Vivan ${ }^{3}$
}

${ }^{1}$ Federal Rural University of Pernambuco - Dept. of Agronomy, R. Dom Manoel de Medeiros, s/n - 52171-900 Recife, PE - Brazil.

2Mato Grosso Cotton Institute, R. Eng. Edgard Prado Arze, 1777 - 78049-015 - Primavera do Leste, MT - Brazil.

${ }^{3}$ Mato Grosso Agricultural Research Foundation, Av. Antônio Teixeira dos Santos, 1559 - 78750-000 - Rondonópolis, MT - Brazil.

*Corresponding author <jorge.torres@ufrpe.br>

Edited by: Alberto Soares Corrêa

Received November 11, 2016

Accepted April 09, 2017
ABSTRACT: The boll weevil colonizes cotton fields as early as cotton squaring, causing signifcant losses due to feeding and protected development inside fruiting structures throughout crop phenology. Successful control depends on control of adults and their accurate detection when they colonize the crops. The commercial trap and boll weevil attract-and-control tubes (BWACT) are the only available tools to monitor and attract-and-kill boll weevil, despite limitation in efficacy, and insecticide in BWACT is not allowed in organic production. A grandlure-and-glue reusable and insecticide-free tube (GGT) made with polyvinyl chloride tube, smeared with entomological glue, and lured with pheromone was tested to detect boll weevil activity across various seasons. Boll weevil showed activity during growing season and off-season from 2009 to 2012 in the Semiarid and with higher numbers captured in GGT in comparisons to commercial traps. GGT was able to detect early weevils in the field right after planting. Further, the overall averages resulted in 34-, 16.8-, and 7.5-times more weevils captured in GGTs compared to the traps during stalk destruction in the Semiarid 2011 and Cerrado season 2012/13 and during the harvesting period in the Cerrado season 2011/12, respectively. Therefore, boll weevils were captured actively during season and off-season and early captures obtained in GGT compared to traps showed a better correlation between captures and square damage.

Keywords: Anthonomus grandis, control threshold, cotton pest, survey

\section{Introduction}

Monitoring of the boll weevil population in the cotton ecosystem (in the field, surrounding areas, and between crop seasons) has been a core component of the decision-making process for integrated management of this key cotton pest. Traps with the boll weevil pheromone have been widely used to detect this pest. The data collected, however, are not sufficient to define pest density in the field and the damage intensity to the crop (Lloyd et al., 1981). Therefore, cotton scouting for boll weevils relies on visual inspection of a certain number of fruiting structures (mainly flower buds exhibiting feeding and oviposition punctures) per area to determine the economic threshold level.

The boll weevil, Anthonomus grandis Boh. (Coleoptera: Curculionidae), is the major cotton pest where it occurs. In Brazil, boll weevil has driven the crop-pest management decisions despite the great complex of pest species occurrence (Bélot et al., 2016). The earlier the infestation takes place, the greater are the losses, because the abundant availability of fruiting structures supports pest reproduction (Neves et al., 2010). Therefore, the main objective of any research on boll weevil survey is the earliest possible detection of the insect arrival in the field in order to implement the best control tactic.

This paper reports our efforts to adapt a permanent and recyclable tube, easy to be prepared and install in a boll weevil trap without insecticide, for detection and collection (killing by arrestment in glue) of weevils arriving early in the season when plant sources are not yet in strong competition with males producing phero- mone after feeding on squares (Leggett, 1980). We hope to provide cotton growers with a unique tool that can be used for growing cotton under both insecticide-based and organic-based management systems. Organic and agroecological cotton production is a growing activity among small holders, especially, in the Northeast of Brazil using colored fiber cottons. Thus, the specific objectives of this work were to determine the efficacy of various colors of grandlure-and-glue polyvinyl chloride (PVC) tube traps prior to test the best PVC tube to survey boll weevil populations during the growing season in order to correlate capture rates in the tubes with fruit damage and adult numbers in plant terminals as well as to trap weevils moving in and out from cotton fields.

\section{Materials and Methods}

The study was conducted using various cotton fields located in the Semiarid and Cerrado cotton growing regions of Brazil. The fields in the Semiarid were located in the municipality of Surubim, Pernambuco State, Brazil (Furnas: 0753'48.9" S, 35²4'19.2" W, 394 $\mathrm{m}$ a.s.l.) and Frei Miguelinho, Pernambuco State, Brazil (07 ${ }^{\circ} 55^{\prime} 09.3^{\prime \prime} \mathrm{S}, 35^{\circ} 51^{\prime} 45.6^{\prime \prime} \mathrm{W}, 309 \mathrm{~m}$ a.s.1.) from Apr 2009 to Mar 2012. The trial in the Cerrado was carried out during the 2011/12 and 2012/13 seasons with two fields located in the municipality of Primavera do Leste, Mato Grosso State, Brazil $\left(15^{\circ} 24^{\prime} 51.6^{\prime \prime}\right.$ S, 54 $26^{\circ} 24.1^{\prime \prime}$ W, $360 \mathrm{~m}$ a.s.l.; $15^{\circ} 48^{\prime} 44.3^{\prime \prime}$ S, $53^{\circ} 48^{\prime} 09.3^{\prime \prime}$ W, $630 \mathrm{~m}$ a.s.l.), two fields in Itiquira, Mato Grosso State, Brazil $\left(16^{\circ} 59^{\prime} 34 ; 6^{\prime \prime} \mathrm{S}, 54^{\circ} 49^{\prime} 22.5^{\prime \prime}\right.$ W, $515 \mathrm{~m}$ a.s.l.; $16^{\circ} 58^{\prime} 28.4^{\prime \prime}$ S, 54 $50^{\prime} 13.9^{\prime \prime}$ W, $525 \mathrm{~m}$ a.s.l.) and two fields in Ron- 
donópolis Mato Grosso State, Brazil (1855'04.3" S, $54^{\circ} 44^{\prime} 26.5^{\prime \prime} \mathrm{W}, 229 \mathrm{~m}$ a.s.1.; $16^{\circ} 41^{\prime} 20.3^{\prime \prime} \mathrm{S}, 54^{\circ} 40^{\prime} 38.2^{\prime \prime}$ W, $237 \mathrm{~m}$ a.s.l.).

\section{Boll weevil monitoring in the Semiarid}

The efficacy of Grandlure-and-glue PVC tubes painted in three colors was compared based on the number of weevils collected during three growing seasons (Apr-Sept) and intercropping periods (Oct-Mar). Thus, the boll weevil population was monitored using $1.5-\mathrm{m}$ high, 25-mm-diameter PVC tubes coated with one of three colors: yellow (2027-E), green (2595-E; Eucatex, São Paulo, Brazil), or green fluorescent (Renner, São Paulo, Brazil). After the paint dried, 10 holes $(4 \mathrm{~mm}$ diameter, $8 \mathrm{~cm}$ spaced) were made along the tube with the aid of a power drill. One of these holes was located at one end of the tube and used to fix the pheromone septa using a piece of metal wire.

Three cotton fields ranging from 2 to 8 ha each were cultivated without insecticide input and planted with one of the three cotton varieties (BRS Rubi, BRS 201, or Acala 90, depending on the season and area). The tubes were spaced $60-100 \mathrm{~m}$ apart and at $2 \mathrm{~m}$ outside the field border, alternating tubes with different colors. Each tube was driven $20 \mathrm{~cm}$ into the soil, fitted with one pheromone rubber septum BW10 [Grandlure $2.1 \%$ $\left(21 \mathrm{mg} \mathrm{kg}^{-1}\right)+$ rubber $97.9 \%$;] on its top end hole, and smeared with a thin layer of approximately $23 \mathrm{~g}$ of entomological glue (Biocontrole, São Paulo, Brazil) along $1 \mathrm{~m}$ of its top. We name this apparatus a 'Grandlure-and-glue tube' (GGT).

Nine GGTs - three of each color - were installed in each field once per month. Each month from Apr 2009 through Mar 2012, tubes were installed randomly around the field. They received lures at the beginning of the $2^{\text {nd }}$ week of the month and were inspected 1315 days later. At the day of evaluation, the tubes were collected and wrapped with plastic film, which was removed before counting the insects in the laboratory. After these monthly evaluations, the GGTs were cleaned using a twisted nylon cord, wrapped with plastic film, and kept for reuse during the next month as described in Neves et al. (2013a).

\section{Boll weevil populations in the Semiarid across cotton crop development}

To obtain more detailed data on the efficacy of GGTs to detect and capture boll weevils during the various cotton developmental stages, this study was carried out in two cotton fields of 6 ha each, cultivated without insecticide input during the 2011 cotton-growing season. GGTs painted in the same three colors (yellow, green, and green fluorescent) were compared with the conventional commercial trap (Biocontrole, São Paulo, Brazil) marketed in Brazil to monitor boll weevils. Each GGT or trap received a similar pheromone BW10 rubber septum.

GGTs and traps were installed in each field at each of the seven cotton growth stages: after planting (crop
< 35 days old), at squaring (35-55 days), at flowering to young boll (55-75 days), at boll formation (75-100 days), at open boll (100-125 days), at harvest (125-140 days), and at stalk destruction (> 150 days). Three GGTs per color and three traps were used in each area spaced every 60-100 m. The trap displays around the field border consisted of three sets of traps composed of one GGT per color installed plus one trap. For height consistency, the traps were fixed on the upper end of a 1.5-m-long PVC tube of original brown color driven $20 \mathrm{~cm}$ into the soil. The same evaluation schedule was adopted for GGTs and traps with one installation per month at the $2^{\text {nd }}$ week of each month followed by 13-15 days of collection period. The traps were reinstalled in the same site in the field in successive months. On the day of evaluation, the weevils captured were counted and then removed with the aid of forceps.

\section{Boll weevil populations in the Cerrado across cotton crop development}

This study was carried out during growing seasons 2011/12 and 2012/13 in four and three fields, respectively, varying from 6 to 300 ha each, aiming to validate GGTs as a boll weevil survey tool in commercial large conventional cotton fields. Each season was considered as one repeated measure over time and each received three tubes of each color and three traps. Pest management was specific for each field with insecticide applications based on pest species infestation determined by a field survey carried out weekly. The insecticides in use consisted of 2-5 applications of methomyl, endosulfan, and malathion, and 6-10 applications of the pyrethroids zeta-cypermethrin, beta-cypermethrin, or lambda-cyhalothrin.

The GGTs in these trials were yellow (Eucatex 2027-E), green (Eucatex 2595-E), and brown (the unmodified marketed color). The study was carried out with four treatments corresponding to GGTs of these three colors plus the commercial trap. During the 2011/12 season, four replications (fields) were included. During the 2012/13 season, the study was conducted using only two treatments: the best GGT color of the 2011/12 season (i.e., yellow) and the trap.

In both cotton seasons, the first sequence of installation - three GGTs with one from each color and one trap - was randomly assigned and repeated for the following sequence of traps and installation dates. GGTs and traps were spaced 80-100 m apart and 2-6 m outside the field borders. Eight surveys were run with the installation of one trap per plant growth stage allowing 13-15 days of collection period: after planting (crop $<35$ days old), at squaring (35-55 days), at flowering to young boll (55-75 days), at boll formation I (75-100 days), at boll formation II (100-125 days), at the open bolls stage (125-150 days), at harvest (150-175 days), and at stalk destruction (> 175 days).

The density of boll weevil and damaged flower buds were simultaneously assessed during the evalua- 
tions of yellow GGTs and traps. Ten plants were inspected per location of tube or trap installation on each field, searching for adult weevils and for flower buds exhibiting feeding or oviposition punctures at the day of counting weevils in the traps. These 10 plants were randomly evaluated along 20 rows of cotton plants beginning at the first row in the border and continued toward the interior of the field skipping one row between inspected plants. On each plant, three flower buds with $\sim 6 \mathrm{~mm}$ diameter and three soft bolls were randomly inspected from the upper part of the plant (i.e., $\mathrm{n}=30$ buds/bolls per location of tube or trap), totaling 120 plants per field and 360 structures per evaluation (i.e. replication).

\section{Statistical analysis}

Prior to the analyses, data from GGTs and traps were standardized to weevils per trap. Further, the number of weevils per three GGTs of each color and three traps installed per field was averaged per GGT or Accountrap; analyses were based on these replication averages. Numbers of collected weevils were submitted to analysis after being subjected to Kolmogorov-Smirnov's normality and Bartlett's homogeneity of variance tests, and the data were $\sqrt{ }(x+0.5)$ transformed to satisfy these assumptions. Further, the numbers of weevils captured during the cropping and intercropping periods covering the seasons 2009/10, 2010/11, and 2011/12 in the Semiarid and those captured in the Accountrap and Yellow GGT across each crop phenology in the Cerrado during the season 2012/13 were compared performing t-tests (PROC TTEST) using either pooled or Satterthwaite methods depending on equal or unequal variance outcome. In addition, analyses of variance (PROC GLM) were performed using the repeated measure procedure with cotton growth stages as a blocking factor for data from trap installed across crop development. Treatment means were separated by Tukey test of honestly significant difference (HSD) at $\alpha=$ 0.05 , per cotton growth stage (plant phenology and stalk destruction). All analyses were performed using SAS (Statistical Analysis System, v. 9.2).

The percentage of damage (fruiting structures with feeding and oviposition punctures) used to build decision on chemical spray, and the number of adult weevils surveyed at progressive stages of cotton development in the Cerrado trial were tested for correlations with the number of weevils captured per yellow GGT or trap, using PROC CORR (Pearson correlation analysis; Statistical Analysis System, v. 9.2).

\section{Results}

\section{Boll weevil monitoring in the Semiarid}

Adult boll weevils were collected during every interval throughout the surveyed period, including the cropping and intercropping periods from 2009 to 2012. However, the average number of boll weevils captured varied between the cropping and intercropping periods, regardless of the color used in the GGT (Table 1). The averages corresponding to 2009/10 and 2011/12 intercropping periods resulted in 10.6- and 10.5-times more weevils, respectively, compared to the cropping seasons 2009/10 and 2011/12. The average numbers of boll weevils captured during the 2010/11 intercropping period did not differ statistically from the numbers during the growing season, for any of the three colors (Table 1). The overall average number of weevils captured per GGT during intercropping periods 2009/10, 2010/11, and $2011 / 12$ varied from 17.6 to $18.3,6.3$ to 8.0 , and 7.6 to 12.3 weevils per GGT, respectively (Table 1 ).

\section{Boll weevil populations in the Semiarid across cotton crop development}

During the 'after planting' and 'squaring' survey periods, collection was low and only GGTs captured any boll weevils (Table 2). As the season moved into stages in which flowers predominated, GGTs captured more weevils compared to the traps $\left(F_{\mathrm{df}=3,23}=12.50, p=0.0002\right)$, with 15 times more weevils captured in the yellow GGT than in the Accountrap. During the boll formation stage (crop 75-100 days old), neither GGTs nor traps caught weevils. Weevil capture was only observed again during the open boll stage, with similar capture rates between GGTs and traps (Table 2). During the last two survey periods, more weevils were captured in GGTs (harvest-

Table 1 - Overall mean ( \pm SEM) number of adult boll weevils captured during crop seasons and intercropping periods throughout three years in the Semiarid using PVC tubes painted in one of three colors, smeared with entomological glue, and lured with the pheromone grandlure.

\begin{tabular}{|c|c|c|c|c|c|}
\hline \multirow{2}{*}{ Years } & \multirow{2}{*}{ Tube color } & \multicolumn{2}{|c|}{ No. of boll weevils per tube } & \multicolumn{2}{|r|}{ t-test } \\
\hline & & Crop season (Apr-Sept) & Intercropping period (Oct-Mar) & $t$ & $p$ \\
\hline \multirow{3}{*}{ 2009-2010 } & Yellow & $1.0 \pm 0.57$ & $17.6 \pm 8.83$ & 3.57 & 0.023 \\
\hline & Green & $1.6 \pm 0.33$ & $18.3 \pm 3.73$ & 8.03 & 0.0013 \\
\hline & Green fluorescent & $2.6 \pm 1.66$ & $18.3 \pm 5.66$ & 3.04 & 0.038 \\
\hline \multirow{3}{*}{ 2010-2011 } & Yellow & $12.3 \pm 2.60$ & $8.0 \pm 3.60$ & 1.00 & 0.38 \\
\hline & Green & $9.6 \pm 1.66$ & $6.3 \pm 2.90$ & 1.05 & 0.35 \\
\hline & Green fluorescent & $13.6 \pm 6.69$ & $7.3 \pm 3.75$ & 0.73 & 0.51 \\
\hline \multirow{3}{*}{ 2011-2012 } & Yellow & $1.0 \pm 0.00$ & $12.0 \pm 1.52$ & 16.1 & $<0.0001$ \\
\hline & Green & $1.0 \pm 0.57$ & $12.3 \pm 3.17$ & 4.20 & 0.014 \\
\hline & Green fluorescent & $1.0 \pm 1.00$ & $7.6 \pm 0.88$ & 3.85 & 0.018 \\
\hline
\end{tabular}

Planting dates: 1 May 2009, 10 Apr 2010, and 30 May 2011. 
Table 2 - Overall mean $( \pm$ SEM) number of boll weevils captured per trap or per grandlure-and-glue tube of one of three colors, along cotton ecosystem phenology in the Semiarid and in the Cerrado.

\begin{tabular}{|c|c|c|c|c|c|}
\hline & \multirow{2}{*}{ Crop phenology (no. days after planting) } & \multirow{2}{*}{ Accountrap } & \multicolumn{3}{|c|}{ Grandlure-and-glue tubes } \\
\hline & & & Yellow & Green & Green fluorescent \\
\hline \multirow{7}{*}{$\begin{array}{l}\text { Semiarid, season } \\
2011\end{array}$} & After planting $(<35)$ & $0.0 \pm 0.00 a$ & $0.3 \pm 0.21 \mathrm{a}$ & $0.5 \pm 0.34 a$ & $0.3 \pm 0.21 \mathrm{a}$ \\
\hline & Squaring (35-55) & $0.0 \pm 0.00 \mathrm{~b}$ & $1.5 \pm 0.22 \mathrm{a}$ & $1.0 \pm 0.44 a b$ & $0.5 \pm 0.22 a b$ \\
\hline & Flowering (55-75) & $0.0 \pm 0.00 \mathrm{a}$ & $0.7 \pm 0.21 \mathrm{a}$ & $0.8 \pm 0.54 a$ & $0.3 \pm 0.21 \mathrm{a}$ \\
\hline & Boll formation (75-100) & $0.0 \pm 0.00 a$ & $0.0 \pm 0.00 a$ & $0.0 \pm 0.00 a$ & $0.8 \pm 0.00 a$ \\
\hline & Open boll (100-125) & $0.3 \pm 0.21 \mathrm{a}$ & $0.5 \pm 0.23 a$ & $0.8 \pm 0.30 a$ & $0.3 \pm 0.21 \mathrm{a}$ \\
\hline & Harvesting (125-140) & $1.7 \pm 0.61 \mathrm{~b}$ & $5.2 \pm 1.16 \mathrm{a}$ & $3.5 \pm 1.43 a b$ & $1.5 \pm 0.85 a b$ \\
\hline & Stalk destruction (> 150) & $2.2 \pm 0.40 c$ & $75.0 \pm 36.72 a$ & $55.0 \pm 21.96 a$ & $18.3 \pm 3.48 b$ \\
\hline & & Accountrap & Yellow & Green & Brown \\
\hline \multirow{8}{*}{$\begin{array}{l}\text { Cerrado, season } \\
2011 / 12\end{array}$} & After planting $(<35)$ & $0.1 \pm 0.11 \mathrm{a}$ & $0.1 \pm 0.16 a$ & $0.5 \pm 0.28 a$ & $0.2 \pm 0.25 a$ \\
\hline & Squaring (35-55) & $0.1 \pm 0.08 \mathrm{a}$ & $0.3 \pm 0.25 a$ & $0.4 \pm 0.25 a$ & $0.1 \pm 0.08 \mathrm{a}$ \\
\hline & Flowering (55-75) & $0.0 \pm 0.00 a$ & $0.1 \pm 0.08 \mathrm{a}$ & $0.1 \pm 0.08 \mathrm{a}$ & $0.1 \pm 0.08 \mathrm{a}$ \\
\hline & Boll formation I (75-100) & $0.5 \pm 0.20 b$ & $2.2 \pm 1.02 \mathrm{a}$ & $2.7 \pm 0.97 a$ & $0.8 \pm 0.66 b$ \\
\hline & Boll formation II (100-125) & $1.8 \pm 0.88 a$ & $7.5 \pm 4.97 a$ & $10.2 \pm 7.85 a$ & $7.8 \pm 5.16 a$ \\
\hline & Open boll (125-150) & $4.4 \pm 3.00 \mathrm{a}$ & $12.5 \pm 6.35 \mathrm{a}$ & $5.6 \pm 2.99 a$ & $4.5 \pm 2.41 \mathrm{a}$ \\
\hline & Harvesting (150-175) & $17.7 \pm 11.79 b$ & $133.1 \pm 47.07 a$ & $42.0 \pm 18.75 a b$ & $85.0 \pm 34.0 \mathrm{a}$ \\
\hline & Stalk destruction (> 175) & $6.9 \pm 4.91 b$ & $44.9 \pm 27.40 a$ & $42.5 \pm 21.00 a$ & $26.6 \pm 12.09 b$ \\
\hline
\end{tabular}

Means within a row followed by the same letter do not differ significantly (Tukey HSD: $p>0.05$ ).

ing stage: $F_{\mathrm{df}=3,23}=6.68, p=0.0044$; stalk destruction: $\left.F_{\mathrm{df}=3,23}=11.26, p=0.0004\right)$ compared to traps. During the stalk-destruction stage, the number of weevils captured by yellow, green, and green fluorescent GGTs was, on average, 34-, 25-, and 8.3-times higher compared to the capture rate in the traps (Table 2).

\section{Boll weevil populations in the Cerrado across cotton crop development}

The average numbers of boll weevils captured by GGTs and traps were low and similar during the early stages of the crop cycle: after planting, squaring, flowering, boll formation II, and open bolls for the survey periods during the 2011/12 crop stages (Table 2). Again, only GGTs were able to capture weevils across all cottongrowing stages during the 2012/13 crop (Table 3).

During the cotton stage corresponding to boll formation I, the yellow and green GGTs captured more weevils than either the Accountrap or the brown marketed color $\left(F_{\mathrm{df}=3,47}=4.21, p=0.013\right)$. On average, 3.8-fold more weevils were captured in yellow and green tubes (Table 2). Likewise, regardless of the color tested, GGTs captured more weevils than the commercial traps did during both harvesting $\left(F_{\mathrm{df}=3,47}=5.77, p=0.0028\right)$ and stalk destruction $\left(F_{\mathrm{df}=3,47}=16.89, p<0.0001\right)$. On average, during these two periods of evaluation, 7.5-, 2.4-, and 4.8-times, and 6.5-, 6.1-, and 3.8-times more weevils were caught in yellow, green, and brown GGTs, respectively, than in traps (Table 2). The total number of boll weevils captured during the cropping season $2011 / 12$ by 12 GGTs of each color and 12 traps totaled 2,409, 1,499, 1,248, and 381 weevils by yellow, green, and brown GGTs and traps, respectively.

Throughout the 2012/13 crop season, the average number of boll weevils captured by yellow GGTs was
Table 3 - Mean ( \pm SEM) number of boll weevils captured per trap or yellow grandlure-and-glue tube (GGT), along cotton ecosystem phenology in the Cerrado during the 2012/13 crop season.

\begin{tabular}{llccl}
\hline Crop phenology & \multirow{2}{*}{\begin{tabular}{c}
\multirow{2}{*}{ (no. days after planting) } \\
Accountrap
\end{tabular}} & Yellow GGT & \multicolumn{2}{c}{ t-test } \\
\cline { 4 - 6 } & & & $t$ & $p$ \\
\hline After planting (< 35d) & $0.3 \pm 0.23$ & $0.6 \pm 0.28$ & 4.00 & 0.081 \\
Squaring (35-55) & $0.0 \pm 0.00$ & $0.2 \pm 0.22$ & 1.00 & 0.35 \\
Flowering (55-75) & $0.2 \pm 0.14$ & $0.8 \pm 0.20$ & 8.00 & 0.022 \\
Boll formation I (75-100) & $0.0 \pm 0.00$ & $0.4 \pm 0.24$ & 3.62 & 0.094 \\
Boll formation II (100-125) & $0.4 \pm 0.24$ & $2.1 \pm 0.45$ & 7.69 & 0.024 \\
Open boll (125-150) & $0.5 \pm 0.29$ & $5.8 \pm 1.30$ & 16.21 & 0.0038 \\
Harvesting (150-175) & $1.8 \pm 0.91$ & $10.3 \pm 3.39$ & 5.84 & 0.042 \\
Stalk destruction (>175) & $8.3 \pm 4.21$ & $139.8 \pm 36.88$ & 14.5 & 0.0051 \\
\hline
\end{tabular}

statistically similar to that for the trap during the survey periods after planting, squaring, and boll formation I (Table 3). Again, only GGTs captured weevils during these periods, with an average $0.2-0.8$ weevils per GGT (Table 3). Furthermore, during the flowering stage the yellow GGT captured about 4-fold more weevils than the traps did (Table 3). Likewise, during the last four crop stages significantly more weevils were captured by yellow GGT compared to traps. In fact, during the harvesting and stalk-destruction periods, the yellow GGTs captured 5.7and 16.8-fold more boll weevils, respectively, compared to traps (Table 3). During the 2012/13 crop season, the total number of boll weevils captured by nine GGTs was 1,444, while the nine traps captured 106 .

Comparison of the percentages of visibly damaged cotton fruiting structures and the numbers of boll weevils captured by yellow GGTs at the squaring and boll formation stages I and II, during the 2011/12 growing season, indicated a statistically significant and positive correlation (Table 4). During the boll formation stage I, the num- 
bers of adult weevils per plant and numbers captured by yellow GGT also exhibited a significant correlation (Table 4). On the other hand, the percentage of damaged fruiting structures and the number of boll weevils captured in traps showed no significant statistical correlation for any surveyed period (Table 4).

Among the cotton growth stages surveyed during the season 2012/13, significant and positive correlation between damaged fruiting structures and boll weevils captured by yellow GGT was detected for flowering and boll formation stage I (Table 4). Again, with traps, no significant correlation was found for any of the cotton stages. The efficacy of collecting boll weevils, as measured by the ratio of boll weevils captured in the yellow GGT to the number captured in the traps, was usually higher in GGT and varied from 1.0 (after planting) to 4.4 (boll formation) during the 2011/12 crop season. This same ratio in the 2012/13 growing season varied from 0.2 to 4.7 (Table 4).

\section{Discussion}

The yellow GGT design tested in this study achieved the objective of detecting early arrivals of boll weevils in the site more precisely than the commercial Accountrap did. It also showed potential for detecting weevils leaving the field to refuge areas during the harvesting and stalk-destruction. Boll weevil usually leaves cotton fields to nearby areas using them as refuge during the intercropping periods (Rummel and Adkisson, 1970; Slosser and Boring, 1980), possibly, the same place where they will come from at the beginning of the next season. Thus, by knowing the refuge sites, the number of GGTs installed can be maximized near these areas when approaching the planting date for a better knowledge of the weevil population. To date, in Brazil, boll weevils are reported to reproduce only on cotton fruiting structures. Therefore, the adults from the last generation of a season should survive to provide the colonizers for the next season and they are doing well using volunteer cotton plants and non-cotton plants for their sustenance (Showler and Abrigo, 2007). Adult boll weevils off-season extend their stay in the site feeding on cotton regrowth, volunteer plants and, according to Ribeiro et al. (2010), on the pollen of at least 19 different plant families, which can be abundant during the intercropping periods. In addition, larger adults emerge from bolls at the end of the season and when combined with low expenditure in energy, due to restrained reproduction in some proportion of the population (Paula et al., 2013), may be enhancing adult survival during offseason period.

Several factors may be responsible for differences on collection between trap and GGT, but besides the pheromone lure, the trap surface and design facilitate capture. Increasing boll weevil captures in either GTT or traps during crop development can be dependent on increasing pheromone attraction with appropriate concentrations (Showler et al., 2006), and cotton plant volatiles or other attractant may enhance the efficacy of the trap (Armstrong et al., 2006; Armstrong, 2010). The addition of plant secondary compound, such as eugenol, may enhance boll weevil response (Armstrong, 2010) and is expected to have an additional effect with grandlure when applied in the trap. Recently, Magalhães

Table 4 - Mean ( \pm SE) percentage of structures (squares and bolls) damaged (\% DS) and numbers of adult boll weevils (BW) per Accountrap (ACT), per yellow grandlure-and-glue tube (GGT), ratio of adults captured between ACT and GGT, and the respective correlation coefficients in parenthesis of these parameters for data from surveys during two cropp seasons in the Cerrado Biome, state of Mato Grosso, Brazil.

\begin{tabular}{|c|c|c|c|c|c|c|}
\hline \multirow{2}{*}{ Cropping season } & \multirow{2}{*}{ Parameters } & \multicolumn{5}{|c|}{ Cotton phenology } \\
\hline & & After planting & Squaring & Flowering & Boll formation I & Boll formation II \\
\hline \multirow[t]{9}{*}{$2011 / 12$} & $\% \mathrm{DS}$ & 0 & $3.33 \pm 1.44$ & $21.58 \pm 10.25$ & $26.75 \pm 10.42$ & $29.08 \pm 7.84$ \\
\hline & BW per 120 plants & 0 & $0.08 \pm 0.08$ & $1.16 \pm 0.71$ & $4.33 \pm 1.75$ & $2.66 \pm 0.95$ \\
\hline & ACT & $0.16 \pm 0.11$ & $0.08 \pm 0.08$ & 0 & $0.50 \pm 0.23$ & $1.83 \pm 0.88$ \\
\hline & GGT & $0.16 \pm 0.16$ & $0.33 \pm 0.25$ & 0 & $2.33 \pm 1.01$ & $7.50 \pm 4.97$ \\
\hline & Ratio GGT/ACT & 1.00 & 4.12 & - & 4.66 & 4.09 \\
\hline & Correlation DS $\times$ ACT & - & $0.16(0.60)$ & - & $0.46(0.78)$ & $0.31(0.32)$ \\
\hline & Correlation DS $\times$ GGT & - & $0.83(0.0008)$ & - & $0.64(0.025)$ & $0.55(0.063)$ \\
\hline & Correlation $\mathrm{BW} \times \mathrm{ACT}$ & - & $-0.09(0.78)$ & - & $0.33(0.28)$ & $0.28(0.38)$ \\
\hline & Correlation BW $\times$ GGT & - & $-0.12(0.71)$ & - & $0.86(0.0003)$ & $0.08(0.80)$ \\
\hline \multirow[t]{9}{*}{$2012 / 13$} & $\% \mathrm{DS}$ & 0 & 0 & $2.20 \pm 0.55$ & $4.43 \pm 0.56$ & $0.77 \pm 2.00$ \\
\hline & BW per 120 plants & 0 & 0 & 0 & 0 & $0.33 \pm 0.23$ \\
\hline & ACT & $0.33 \pm 0.11$ & $0.00 \pm 0.00$ & $0.22 \pm 0.22$ & 0 & $0.44 \pm 0.24$ \\
\hline & GGT & $0.66 \pm 0.16$ & $0.22 \pm 0.22$ & $0.88 \pm 0.20$ & $0.44 \pm 0.24$ & $2.11 \pm 0.45$ \\
\hline & Ratio GGT/ACT & 2.00 & 0.22 & 4.00 & 0.44 & 4.79 \\
\hline & Correlation DS $\times$ ACT & - & - & $-0.18(0.63)$ & - & $-0.03(0.96)$ \\
\hline & Correlation DS $\times$ GGT & - & - & $0.85(0.0035)$ & $0.79(0.011)$ & $0.59(0.091)$ \\
\hline & Correlation $\mathrm{BW} \times \mathrm{ACT}$ & - & - & - & - & $-0.32(0.39)$ \\
\hline & Correlation BW $\times$ GGT & - & - & - & - & $0.21(0.58)$ \\
\hline
\end{tabular}

Pearson correlation coefficients with $p$-values in parenthesis. 
et al. (2012) found that boll weevils responded to cotton plant volatiles emitted when under herbivory by conspecifics, but not by other herbivores. In addition, it is known that substrate color plays an influential role on boll weevil behavior. For instance, the cotton genotype variant with reddish leaves is less preferred by boll weevils (Weaver Junior and Reddy, 1977). Likewise, when kaolin is sprayed on cotton plants, masking their natural green color, the resultant hazy white plant surfaces are less colonized by boll weevils (Neves et al., 2014). In contrast, yellow or green clearly seems to be a preferred color. When Leggett and Cross (1976) tested Saturn traps with different colors, yellow traps performed better than red traps did. In our study, yellow-painted GGTs captured numerically more weevils than the other tested colors and more than commercial traps across the crop season, intercropping period, years, and locations.

The boll weevil population growth is associated to cotton plant reproduction phenology, but boll weevil was active and captured during the entire survey period, including intercropping periods in the Semiarid. The capture of boll weevils during successive intercropping periods shows the complexity required to manage it in the region where the temperature does not impose control by killing or reducing boll weevil development or reducing plant development, particularly where crop remains are not destroyed properly at the end of the crop season. In fact, in two out of three surveyed years in our study, the average number of boll weevils captured per GGT was higher during the intercropping periods. These results may be explained by the fact that in the Semiarid, despite the long dry season, cotton plants continue to hold some green tips hosting pest species supporting off-season weevil population (Neves et al., $2010 ; 2013 b)$. However, there was a switch to high mean numbers of weevils captured during the cropping season 2010 , likely due to the high density of weevils present during the previous intercropping period 2009/2010 (Table 1). The following intercropping period 2010/2011 showed a lower density of weevils compared to the previous intercropping period resulting in low density during the crop season 2011/2012.

At the end of the season, when stalk destruction is mandatory, adult boll weevils leave the cotton field, moving to surrounding crop fields and native vegetation (Rummel and Adkisson, 1970; Slosser and Boring, 1980; Showler, 2006; Ribeiro et al., 2010). This dispersal activity not only assembles an adult population in the refuge area that may survive the intercropping period, but it may also explain the high capture of weevils in tubes and traps at the season end during harvesting and stalk destruction. This dispersal stage, and the equally important period during which surviving weevils are returning to the field at the beginning of the next crop season, provides two particularly critical points for crop management efforts aimed to reduce boll weevil populations thus improve detection and trapping tools such as the yellow GGT can play a major role.
The placement of yellow GGT traps around the field border will help determine the entry site, even when population numbers are still low with unreliable detection with the commercial trap. Such approach, when coupled with subsequent visual inspection, can help guide decisions to treat this border area and should be investigated. If supported by some population threshold, the practice of spraying field borders rather than an entire field minimizes costs, environmental impact, and other risks. It is worth it because conventional pheromone traps have been the only commercially available trap to monitor boll weevil in Brazil. Despite helping detection of boll weevil across the landscape, the traps have presented some limitations. During the growing season (especially from flowering to boll formation stages), the efficacy of these traps is considerably diminished, both due to competition with suitable plant structures for feeding and oviposition and the abundance of potential mates in the field (Lloyd et al., 1981; Guerra and Garcia, 1982). Cotton plants produce large quantities of organic volatiles during the reproductive stage and after $96 \mathrm{~h}$ of boll weevil herbivory (Silva et al., 2015). This suggests the existence of a competition of plant releasing volatiles plus weevils within the plant making the plant more attractive to weevils than the inert trap lured with pheromone.

Furthermore, an efficacious field-border treatment helps to reduce the first generation of weevils in the area (Soria et al., 2013; Lima Junior et al., 2013). However, the decisions for treatments should be supported by some pest population threshold value. Thus, it is important to have a tool able to indicate pest damage inside the field based on the number of weevils captured, with high reliability at every stage of the cotton growth cycle. This need encourages studies to determine a ratio between boll weevils captured in the yellow GGT and square damage, keeping the tube lured continuously and inspecting regularly at short intervals of 5-6 days, for instance, a schedule that is easier and faster than walking through large fields surveying plants. However, both the yellow GGT tube and the commercial trap showed low collection during the stages of cotton plants when they are most susceptible to boll weevil damage - squaring and flowering stages - and improvement must be addressed.

For instance, during the flowering stage for the 2011/12 cropping season, visual inspection revealed damaged structures and adult weevils, but no captures were obtained by either GGTs or traps. Further, during squaring stage in the 2012/13 crop season, boll weevils were captured in GGTs, but not in traps, and visual inspection revealed neither damage nor weevils on plants. Possibly, any threshold based on the number of weevils captured by traps varies with the cotton growth stage. Therefore, any decision to spray should not be based on trap catches alone, but should also consider variables such as crop age in terms of susceptibility regarding the proportion of square and bolls per plant (Showler, 2012) 
as well as weevil population size during the intercropping period (Soria et al., 2013; Lima Junior et al., 2013).

Building a decision threshold does not require the capture of a high number of weevils in the yellow GGT during the cotton reproductive stage. Rather, a result with low relative variance across the tube captures is required in order to obtain high precision to represent the respective crop damage associated with these captures, allowing to keep costs as low as possible (Kogan and Herzog, 1980).

Considering that they are field data, our results showed median correlation coefficients $/ \mathrm{r}=0.55$ and 0.59) during the stage of boll formation II in both years, and they were only marginally significant $(p=0.06$ 0.09). These findings indicate high variability in the data during this crop stage, when all fruiting ages from buds to hard bolls are present. Shorter evaluation intervals are expected to reduce this variability.

Based on our 3-year survey under different environmental and cropping conditions, we conclude that although all four colors used to prepare the GGT captured boll weevils due to the presence of pheromone lure, the yellow GGT performed numerically better across all situations. In addition, this GGT design relies upon entomological glue instead of an insecticide such as cyfluthrin or malathion (McKibben, 1990). Therefore, it shows promise as a reusable trap to both conventional and organic cotton producers, especially in the Semiarid region. Further research should be carried out to correlate weevil capture numbers with extent of field damage and this reusable trap, plus the data we found correlating fruit damage with weevils captured in the trap, also opens the opportunity to set up threshold values to support decisions to treat.

\section{Acknowledgments}

We thank João da Silva Reis and Hermógeno Timóteo for allowing us to use their fields to conduct our studies in the Semiarid, PE, and the 'Mato Grosso Agricultural Research Foundation (FMT)' for his support during the studies in the Cerrado, MT, both in making several fields available and in providing logistic help. Partial financial support was provided by the Foundation for Science and Technology of the State of Pernambuco (FACEPE)' and by the 'Brazilian National Council for Scientific and Technological Development (CNPq)'.

\section{References}

Armstrong, J.S. 2010. Boll weevil (Coleoptera: Curculionidae) response to and volatilization rates of Grandlure when combined with varying doses of eugenol in the extended-life pheromone lure. Journal of Economic Entomology 103: 356-359.

Armstrong, J.S.; Spurgeon, D.E.; Suh, C.P.C. 2006. Comparisons of standard and extended-life boll weevil (Coleoptera: Curculionidae) pheromone lures. Journal of Economic Entomology 99: 323-330.
Bélot, J.L.; Barros, E.M.; Miranda, E.E. 2016. Risks and opportunities: the cotton boll weevil $=$ Riscos e oportunidades: o bicudo-do-algodoeiro. p. 77-11. In: Associação MatoGrossense dos Produtores de Algodão, ed. Challenges of the Cerrado: how to sustain the expansion of production with productivity and competitiveness $=$ Desafios do Cerrado: como sustentar a expansão da produção com produtividade e competitividade. AMPA, Cuiabá, MT, Brazil (in Portuguese).

Guerra, A.A.; Garcia, R.D., 1982. Seasonal patterns of boll weevil response to grandlure-baited traps in the subtropical Rio Grande Valley of Texas. Southwestern Entomology 7: 216220.

Kogan, M.; Herzog, D.C. 1980. Sampling Methods in Soybean Entomology. Springer, New York, NY, USA.

Leggett, J.E. 1980. Boll weevil: competitive and non-competitive evaluation of factors affecting pheromone trap efficiency. Environmental Entomology 9: 416-419.

Leggett, J.E.; Cross, W.H. 1976. The relative importance of color and pheromone in orientation of traps. Environmental Entomology 7: 4-6.

Lima Junior, L.S.; Degrande, P.E.; Miranda, J.E.; Santos, W.J. 2013. Evaluation of the boll weevil Anthonomus grandis Boheman (Coleoptera: Curculionidae) suppression program in the state of Goiás, Brazil. Neotropical Entomology 42: 8288.

Lloyd, E.P.; Knipling, E.F.; McKibben, G.H.; Witz, J.A.; Hartstack, W.A.; Leggett, J.E.; Lockwood, D.F. 1981. Mass trapping for detection, suppression, and integration with other suppression measures against the boll weevil. p. 191203. In: Mitchell, E.R., ed. Management of insect pests with semiochemicals: concepts and practices. Plenum, New York, NY, USA.

Magalhães, D.M.; Borges, M.; Laumann, R.A.; Sujii, E.R.; Mayon, P.; Caulfield, J.C.; Midega, C.A.O.; Khan, Z.R.; Pickett, J.A.; Birkett, M.A.; Moraes, M.C.B. 2012. Semiochemicals from herbivory induced cotton plants enhance the foraging behavior of the cotton boll weevil, Anthonomus grandis. Journal of Chemical Ecology 38: 1528-1538.

McKibben, G.H.; Smith, J.W.; McGovern, W.L. 1990. Design of an attract-and-kill device for the boll weevil (Coleoptera: Curculionidae). Journal of Entomological Science 25: 581-586.

Neves, R.C.S.; Torres, J.B.; Silva, M.N.B. 2010. Appropriate time for pruning cotton plant aiming at pest control. Pesquisa Agropecuária Brasileira 45: 1342-1350 (in Portuguese, with abstract in English).

Neves, R.C.S.; Vivan, L.M.; Torres, J.B. 2013a. Ecological option to survey and to mass trapping boll weevil = Opção Ecológica para o Monitoramento e Coleta Massal do Bicudodo-Algodoeiro. Universidade Federal Rural de Pernambuco, Recife, PE, Brazil. (Informativo REDALGO, 6) (in Portuguese).

Neves, R.C.S.; Showler, A.T.; Pinto, E.S.; Bastos C.S.; Torres, J.B. 2013b. Reducing boll weevil populations by clipping terminal buds and removing abscised fruiting bodies. Entomology Experimental et Applicata 146: 276-285.

Neves, R.C.S.; Colares, F.; Torres, J.B.; Bastos, C.S. 2014. Rational practices to manage boll weevils colonization and population growth on family farms in the semiárido region of Brazil. Insects 5: 818-831. 
Paula, D.P.; Claudino, D.; Timbó, R.V.; Miranda, J.E.; Bemquerer, M.P.; Ribeiro, A.C.J.; Sujii, E.R.; Fontes, E.M.G.; Pires, C.S.S. 2013. Reproductive dormancy in boll-weevil from populations of the midwest of Brazil. Journal of Economic Entomology 106: 86-96.

Ribeiro, P.A.; Sujii, E.R.; Diniz, I.R.; Medeiros, M.A.; SalgadoLaboriau, M.L.; Branco, M.C.; Pires, C.S.S.; Fontes, E.M.F. 2010. Alternative food sources and overwintering feeding behavior of the boll weevil, Anthonomus grandis Boheman (Coleoptera: Curculionidae) under the tropical conditions of central Brazil. Neotropical Entomology 39: 28-34.

Rummel, D.R.; Adkisson, P.L. 1970. Distribution of boll weevilinfested cotton fields in relation to overwintering habitat in the High and Rolling Plains of Texas. Journal of Economic Entomology 63: 1906-1909.

Showler, A.T. 2006. Short-range dispersal and overwintering habitats of boll weevils (Coleoptera: Curculionidae) during and after harvest in the subtropics. Journal of Economic Entomology 99: 1152-1160.

Showler, A.T. 2012. The conundrum of chemical boll weevil control in subtropical regions. p. 437-448. In: Parveen, F., ed. Insecticides-pest engineering. InTech, Rijeka, Croatia.

Showler, A.T.; Robacker, D.C.; Salgado, E.; Cantú, R.V. 2006. Grandlure dosage and attraction of boll weevils (Coleoptera: Curculionidae). Journal of Economic Entomology 99: 16751681.
Showler, A.T.; Abrigo, V. 2007. Common subtropical and tropical nonpollen food sources of the boll weevil (Coleoptera: Curculionidae). Environmental Entomology 36: 99-104.

Silva, J.B.; Silva-Torres, C.S.A.; Moraes, M.C.B.; Torres, J.B.; Laumann, R.A.; Borges, M. 2015. Interaction of Anthonomus grandis and cotton genotypes: biological and behavioral responses. Entomology Experimental et Applicata 156: 238253.

Slosser, J.E.; Boring, E.P. 1980. Shelterbelts and boll weevils: a control strategy based on management of overwintering habitat. Environmental Entomology 9: 1-6.

Soria, M.F.; Thomazoni, D.; Tachinardi, R.; Degrande, P.E. 2013. Alert for the Cotton Boll Weevil: Brief Overview of the 2012/13 Pre-Harvest Season and Actions to Combat the Plague = Alerta para o Bicudo-do-Algodoeiro: Breve Panorama Pré-Safra 2012/13 e Ações para o Combate da Praga. IMAmt, Primavera do Leste, MT, Brazil. (Circular Técnica, 3) (in Portuguese).

Weaver Junior, J.B.; Reddy, M.S. 1977. Boll weevil non-preference, antibiosis and hatchability studies utilizing cotton lines with multiple non-preferred characters. Journal of Economic Entomology 70: 283-285. 